\title{
Non-isothermal crystallization kinetics of UHMWPE composites filled by oligomer-modified $\mathrm{CaCO}_{3}$
}

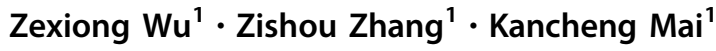

Received: 25 July 2018/Accepted: 31 May 2019/Published online: 14 June 2019

(C) The Author(s) 2019

\begin{abstract}
The processability of ultrahigh molecular weight polyethylene (UHMWPE) improved by oligomer-modified calcium carbonate $\left(\mathrm{CaCO}_{3}\right)$ was observed in our previous work. In order to understand the effect of oligomer-modified $\mathrm{CaCO}_{3}$ on the crystallization of UHMWPE, the non-isothermal crystallization behavior and crystallization kinetics of UHMWPE composites filled by oligomer-modified $\mathrm{CaCO}_{3}$ was studied by differential scanning calorimetry in this work. Jeziorny and Mo methods were used to describe the non-isothermal crystallization kinetics of UHMWPE composites. The effect of modified filler content and cooling rate on the crystallization temperature and crystallization rate was discussed. The heterogeneous nucleation of modified $\mathrm{CaCO}_{3}$ slightly increases the crystallization temperature of UHMWPE. The crystallization enthalpy of UHMWPE composites is significantly higher than that of UHMWPE. The crystallization rate of UHMWPE composites depends on the filler contents and cooling rate.
\end{abstract}

Keywords Non-isothermal crystallization kinetics $\cdot$ Ultrahigh molecular weight polyethylene · Oligomer-modified calcium carbonate $\cdot$ Crystallization

\section{Introduction}

Ultrahigh molecular weight polyethylene (UHMWPE) is an excellent thermoplastic crystalline plastic [1-4]. In comparison with other polyethylene, UHMWPE has lower coefficient of friction [5-7], higher mechanical strength $[8,9]$ and abrasion resistance [10-12]. Thus, UHMWPE has a wider foreground of application for pipeline industry [13, 14], biological medicine [15-17], textile industry $[18,19]$ and so on. Nevertheless, UHMWPE has extremely high molecular weight so that it is difficult to be processed

Kancheng Mai

cesmkc@mail.sysu.edu.cn

Zexiong $\mathrm{Wu}$

wuzx3@mail2.sysu.edu.cn

Zishou Zhang

zhzish@mail.sysu.edu.cn

1 Key Laboratory of Polymeric Composites and Functional Materials of Ministry of Education, Guangdong Provincial Key Laboratory for High Performance Polymer-Based Composites, Materials Science Institute, School of Chemistry, Sun Yat-sen University, Guangzhou 510275, People's Republic of China by common processing method. Aim at this situation, a lot of researchers prepared a series of UHMWPE-based compounds to improve its performance [9, 20-24]. Meanwhile, UHMWPE as a crystalline polymer, addition of other materials can change the crystallization property of UHMWPE, which can influence the UHMWPE performance [25-29]. Therefore, it is necessary to study the crystallization behavior of modified UHMWPE materials.

Sattari et al. [30] reported the non-isothermal crystallization and melting behavior of UHMWPE hybrid composites reinforced with short carbon fiber (SCF) and nano$\mathrm{SiO}_{2}$ particles. It is observed that adding SCF to UHMWPE increased the melting peak temperatures and the crystallinity of UHMWPE. The amounts of nano- $\mathrm{SiO}_{2}$ had no obvious effect on melting temperatures of UHMWPE and decreased the crystallinity of UHMWPE. Ozawa-Avrami method can be used to describe the non-isothermal crystallization kinetics of the composites.

Liu et al. [31] prepared a novel antibacterial UHMWPE/ chlorhexidine acetate (CA)-montmorillonite (MMT) composites and investigated the crystallization kinetics of UHMWPE, UHMWPE/MMT, UHMWPE/CA and UHMWPE/CA-MMT. It is observed that the CA and MMT 
exhibited strong heterogeneous nucleation to increase the crystallization temperatures of UHMWPE. Addition of CA lowered the melting temperature of UHMWPE due to its plastization. The results of crystallization kinetics indicated that the addition of CA decreased the crystallization rate and broadened the range of crystal growth temperature, while MMT increased the crystallization rate due to its heterogeneous nucleation.

Zhang et al. [32, 33] studied the non-isothermal crystallization kinetics of UHMWPE in liquid paraffin (LP) systems and used the Avrami method modified by Jeziorny and Mo to describe the influence of UHMWPE content and cooling rate on crystallization mechanism and spherulitic structure of UHMWPE. Addition of LP increased the crystallization rate of UHMWPE. The Avrami plots of UHMWPE and UHMWPE/LP blends show a good linearity. At the primary crystallization stage, it is found that the Avrami exponent $n$ is variable around 5 and decreases slightly as the cooling rate decreases. High values of $n_{1}$ for UHMWPE and UHMWPE/ LP blends may be generated from their high viscosities yielding a more complicated crystallization mechanism. In addition, the extent of secondary crystallization increases with increasing cooling rate. The Avrami exponent $n_{2}$, ranging from 0.80 to 1.96 , indicated the simpler crystallization mode. Further, the value of $F(T)$ in the Mo method increased with an increase in relative crystallinity and UHMWPE content in the blends.

Shen et al. [34] researched the influence of compatibilizer and dispersant on the non-isothermal crystallization behavior of HDPE/UHMWPE/hydroxyapatite blends. Analyzed by Jeziorny method, the value of Avrami exponent $n$ is between 2.7 and 3.5. At the same temperature, adding compatibilizer and dispersant increased the crystallization rate, while decreased the half crystallization time and the activation energy of crystallization. In addition, the compatibilizer and dispersant also improved the mechanical properties of blends.

Except as mentioned above, the effect of UHMWPE on the crystallization behavior and crystallization kinetics of HDPE has been reported [13, 35]. Nevertheless, fewer investigation focus on the crystallization behavior and the non-isothermal crystallization kinetics UHMWPE (a)

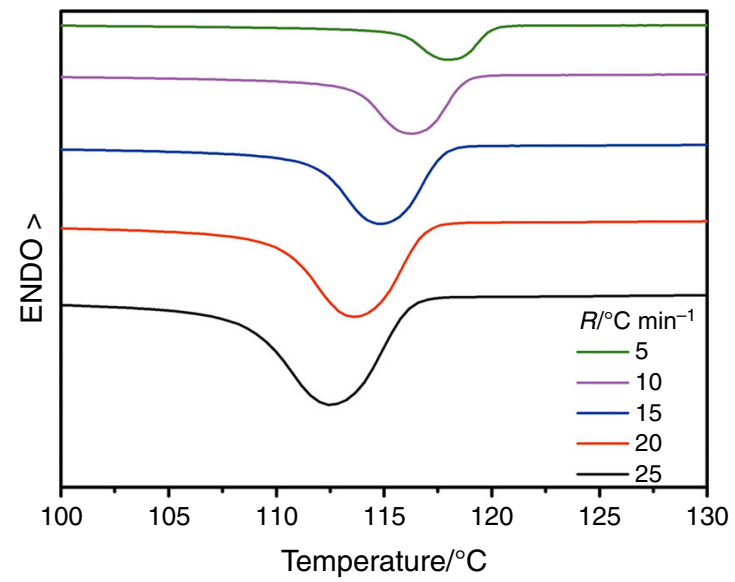

(b)

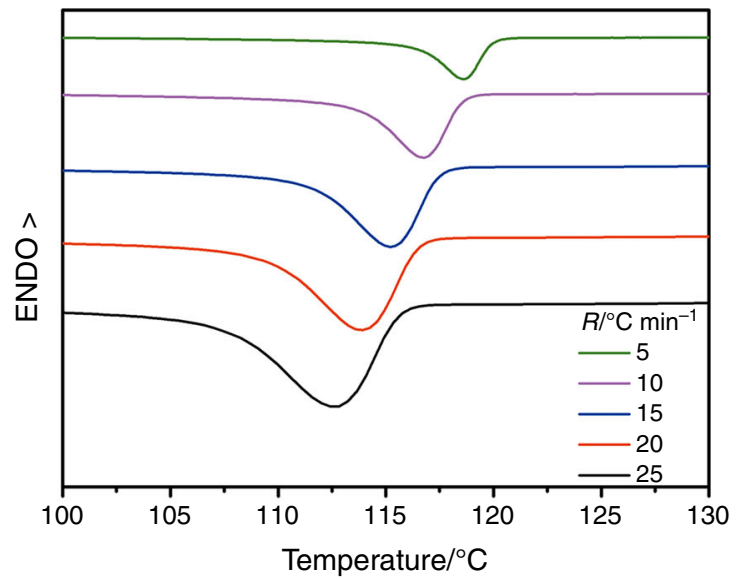

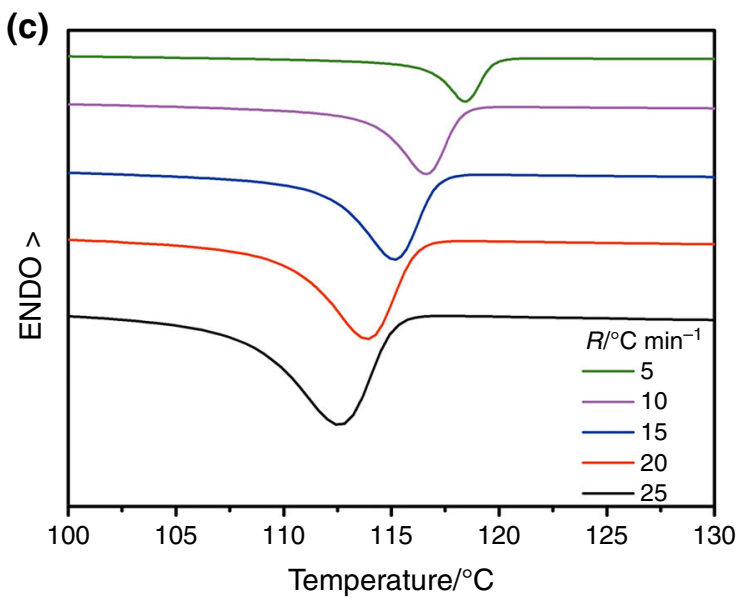

Fig. 1 DSC crystallization curves for PEW-g-CaCO $3 / \mathrm{UHMWPE}$ at different cooling rate $\mathrm{PEW}-\mathrm{g}-\mathrm{CaCO}_{3} / \mathrm{wt} \%$ : a 0 , b 10 and c 20 

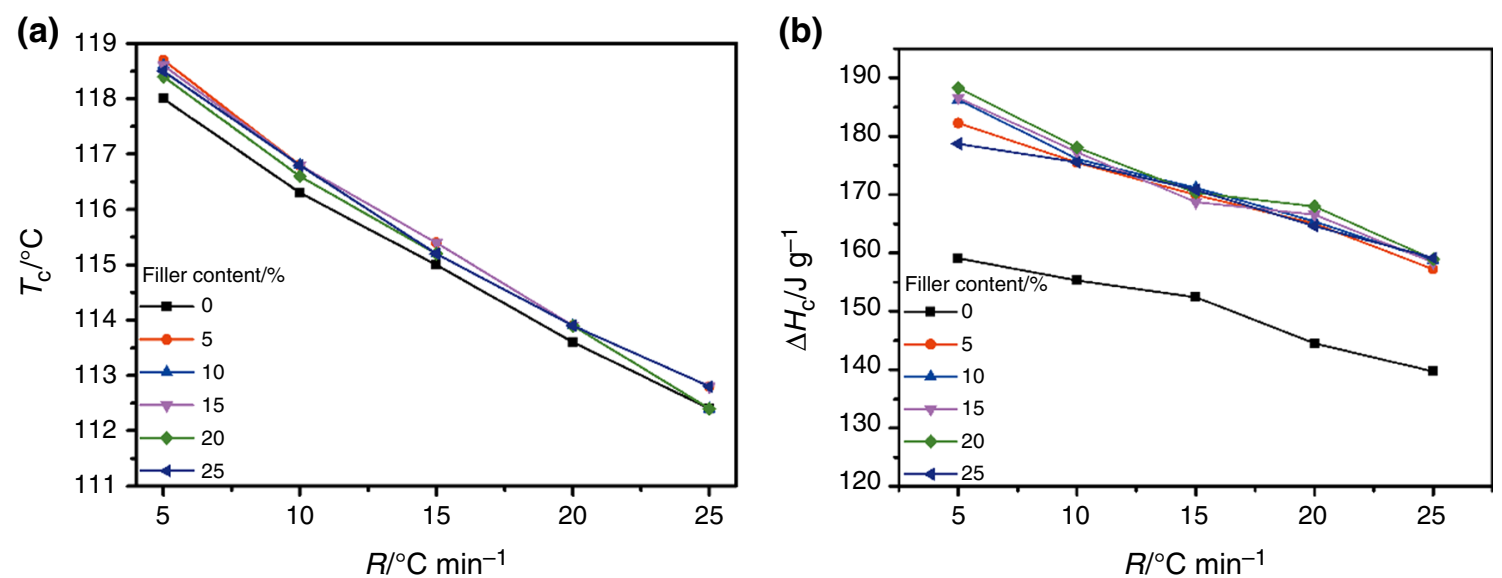

Fig. 2 Plots of crystallization peak temperature and crystallization enthalpy versus cooling rate
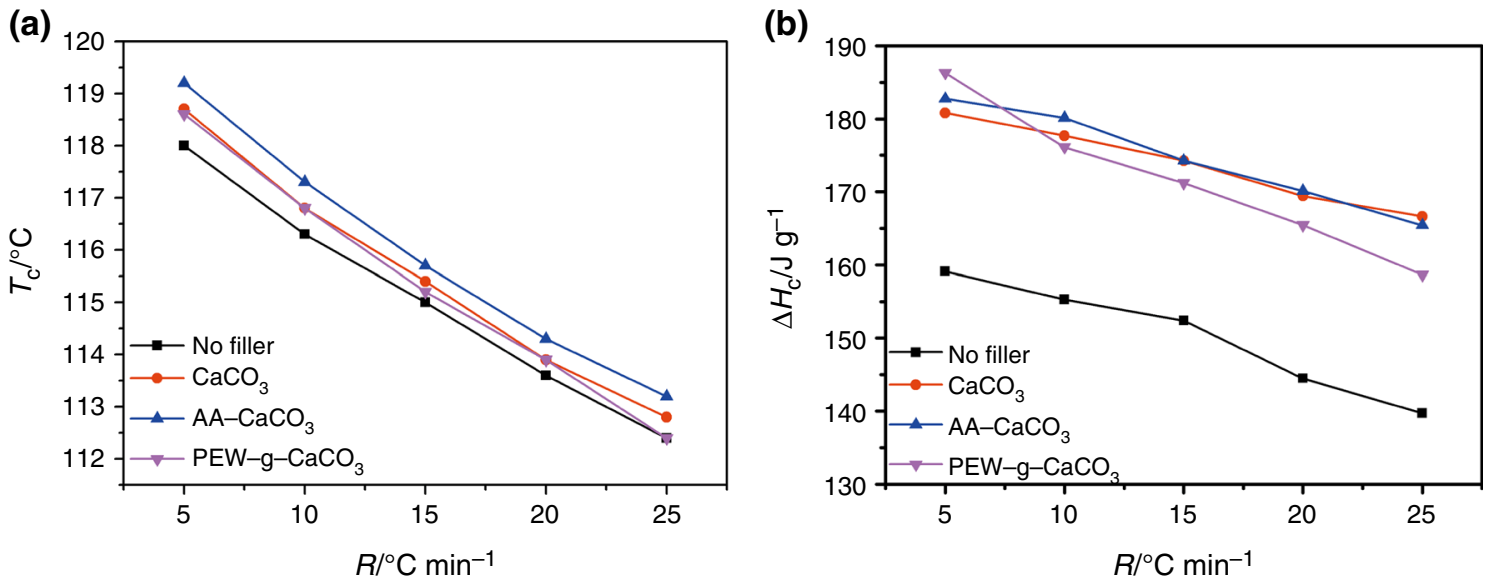

Fig. 3 Plots of crystallization peak temperatures and crystallization enthalpy versus cooling rate for UHMWPE composites filled by $10 \%$ filler

composites filled by inorganic particles. In our previous works, a new UHMWPE composite filled by oligomermodified $\mathrm{CaCO}_{3}$ was prepared in our laboratory. It is found that our prepared oligomer-modified $\mathrm{CaCO}_{3}$ can improve the processability of UHMWPE [36]. In order to understand the effect of oligomer-modified $\mathrm{CaCO}_{3}$ on the crystallization of UHMWPE, the crystallization behavior of UHMWPE composites was investigated by DSC, while the nonisothermal crystallization kinetics was described by different kinetic models. The influence of the modified filler on the UHMWPE crystallization was discussed in this article.

\section{Experimental}

\section{Materials}

UHMWPE $\left(M_{\mathrm{w}} 2.2 \times 10^{6}\right)$ was purchased from Mitsui Chemicals, Japan. PE wax (Product No.1020, Mw about 2000-5000 and melt point at $116^{\circ} \mathrm{C}$ ) was provided by SCG, Thailand. Micro- $\mathrm{CaCO}_{3}$ was provided by Keynes nanomaterial (Lianzhou, China). Benzoyl peroxide (BPO) and acrylic acid (AA) were purchased from Damao Chemical (Tianjin, China).

\section{Sample preparation}

In order to obtain acrylic acid (AA)-modified calcium carbonate $\left(\mathrm{AA}-\mathrm{CaCO}_{3}\right), 500 \mathrm{~g} \mathrm{CaCO}_{3}$ was added in $2.5 \mathrm{~L}$ ethyl alcohol at room temperature, then $40 \mathrm{~g}$ AA was added and stirred $20 \mathrm{~min}$ by mechanical stirring so that $\mathrm{CaCO}_{3}$ reacted with AA thoroughly. Then, the solvent was volatilized at room temperature, and the product of AAmodified calcium carbonate $\left(\mathrm{AA}-\mathrm{CaCO}_{3}\right)$ was dried in at $80{ }^{\circ} \mathrm{C}$ for $1 \mathrm{~h}$.

The $\mathrm{AA}-\mathrm{CaCO}_{3}$, PE wax (mass ratio 8:2) and 0.5 mass\% BPO (relative to $\mathrm{CaCO}_{3}$ ) as initiator were mixed in mixer chamber at $150{ }^{\circ} \mathrm{C}$ for $10 \mathrm{~min}$. The long chain-modified $\mathrm{CaCO}_{3}\left(\mathrm{PEW}-\mathrm{g}-\mathrm{CaCO}_{3}\right)$ was prepared due to reaction between $\mathrm{PEW}$ and $\mathrm{AA}$. Composites of UHMWPE filled by different contents of $\mathrm{PEW}-\mathrm{g}-\mathrm{CaCO}_{3}$ were prepared in mixer chamber at $190{ }^{\circ} \mathrm{C}$ for $10 \mathrm{~min}$. 
(a)

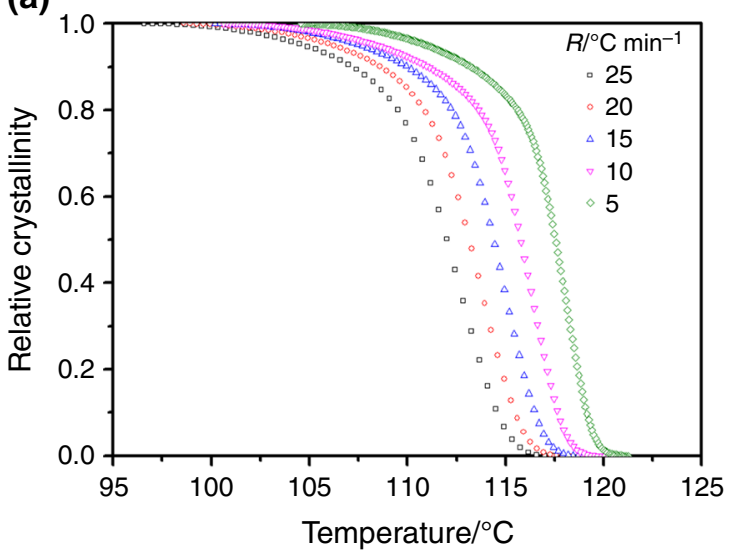

(b)

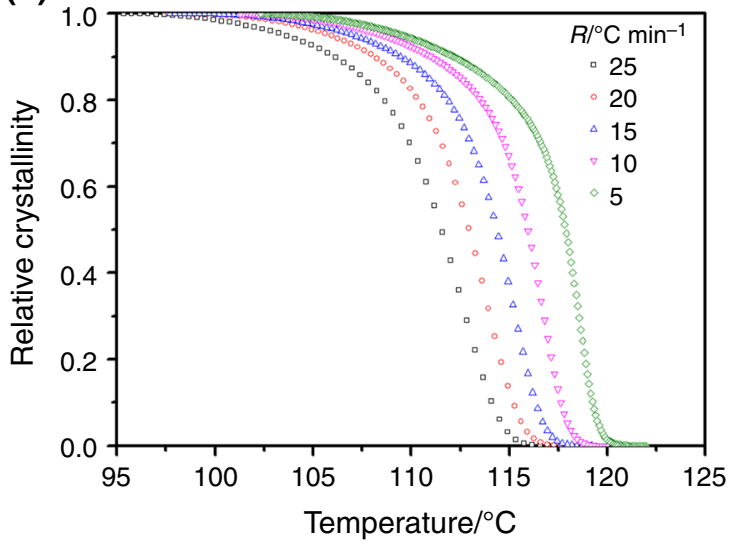

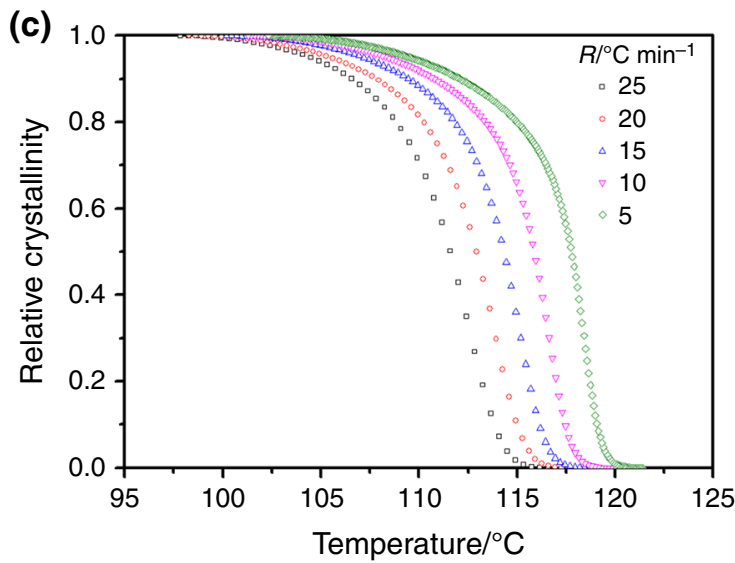

Fig. 4 Curves of relative crystallinity versus temperature of $\mathrm{PEW}-\mathrm{g}-\mathrm{CaCO}_{3} / \mathrm{UHMWPE} \mathrm{PEW}-\mathrm{g}-\mathrm{CaCO} / \mathrm{wt} \%$ : a 0 , b 10 and $\mathbf{c} 20$

\section{Sample characterization}

The melting and crystallization behavior of UHMWPE composites were measured by differential scanning calorimetry (DSC) at nitrogen atmosphere with the DSC8500 (PE, America), calibrated with indium. About 2$3 \mathrm{mg}$ sample was firstly heated up to $180{ }^{\circ} \mathrm{C}$ at the rate of $100{ }^{\circ} \mathrm{C} \min ^{-1}$ and kept this temperature for $3 \mathrm{~min}$ to eliminate the thermal history of sample. Then, the sample was cooled at the rate of $5,10,15,20,25{ }^{\circ} \mathrm{C} \mathrm{min}{ }^{-1}$ from 180 to $60{ }^{\circ} \mathrm{C}$ to obtain the non-isothermal crystallization curves. At last, the sample was reheated up to $180{ }^{\circ} \mathrm{C}$ at the rate of $10{ }^{\circ} \mathrm{C} \mathrm{min}{ }^{-1}$ to obtain the melting curves. The crystallinity of sample $\left(X_{\mathrm{c}}\right)$ is calculated by Eq. 1 .

$X_{\mathrm{c}} \%=\frac{\Delta H_{\mathrm{m}}}{\Delta H_{\mathrm{m}}^{0} \cdot w} \times 100 \%$

where $\Delta H_{\mathrm{m}}$ is the melting enthalpy of sample measured by DSC, $\Delta H_{\mathrm{m}}^{0}$ is the melting enthalpy of $100 \%$ crystalline UHMWPE $\left(290 \mathrm{~J} \mathrm{~g}^{-1}\right)$ [30] and $w$ is the mass content of UHMWPE in the composites.

\section{Results and discussion}

\section{Effect of modified- $\mathrm{CaCO}_{3}$ on non-isothermal crystallization behavior of UHMWPE}

Figure 1 shows the crystallization curves of UHMWPE composites cooled at different rates. The plots of crystallization peak temperatures and crystallization enthalpy versus cooling rate are shown in Fig. 2. It is observed that the crystallization peak of UHMWPE is shifted to the lower temperature and crystallization peak becomes wider with an increase in cooling rates. The crystallization peak temperature of UHMWPE composites is higher than that of UHMWPE, and the contents of PEW-g- $\mathrm{CaCO}_{3}$ have little influence on the crystallization peak temperature of UHMWPE composites. The crystallization enthalpy of composites also decreases with an increase in cooling rate. At the same cooling rate, the crystallization enthalpy of composites is significantly higher than that of UHMWPE and increases with an increase in the PEW-g- $\mathrm{CaCO}_{3}$ contents at cooling rate of $5{ }^{\circ} \mathrm{C} \mathrm{min}{ }^{-1}$. However, the contents of PEW-g- $\mathrm{CaCO}_{3}$ have little influence on the 
(a)

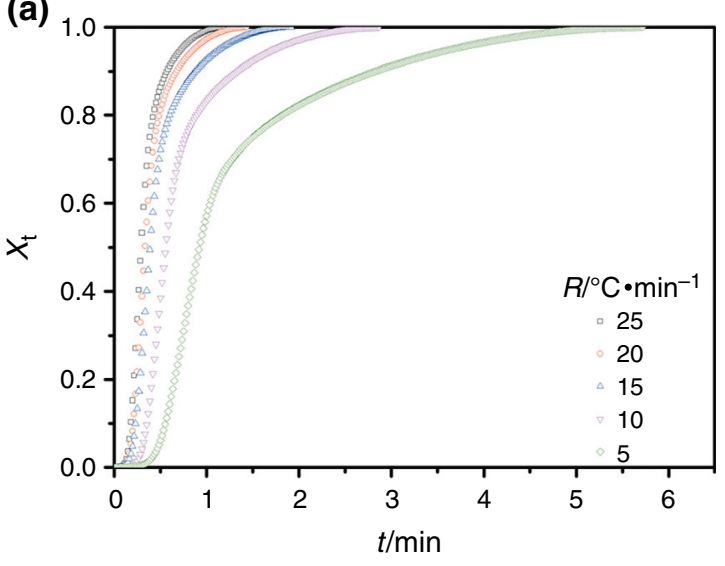

(b)

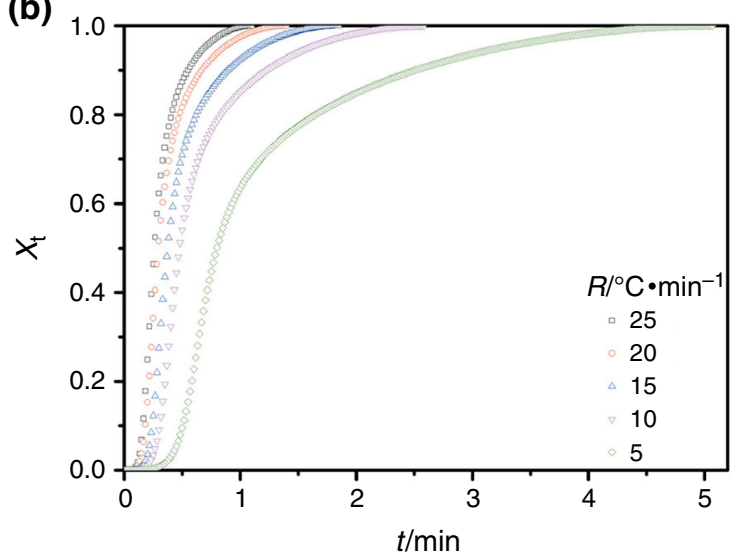

(c)

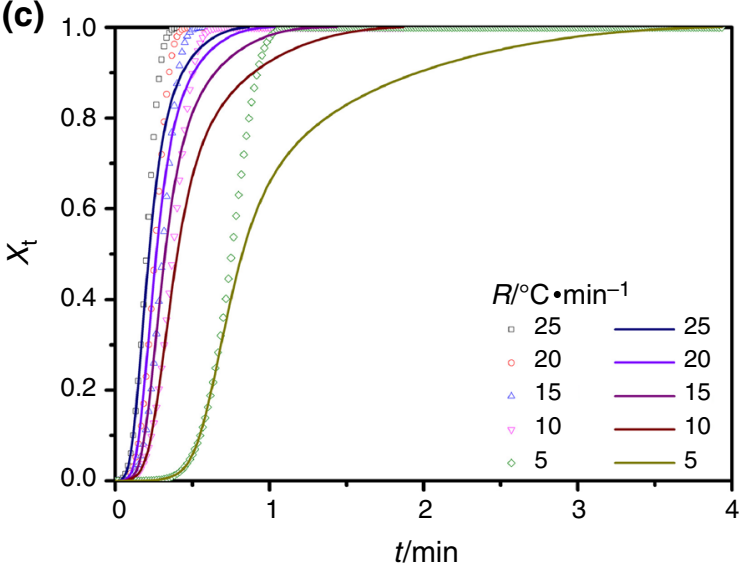

Fig. 5 Curves of relative crystallinity versus time of PEW-g-CaCO$/ 2$ UHMWPE PEW-g-CaCO$/ \mathrm{wt} \%$ : a 0 , b 20 and c 10 . Line: the experiment results, point: the kinetic calculation results

crystallization enthalpy of UHMWPE composites at high cooling rate.

The crystallization enthalpy of composites decreases with an increase in cooling rate, while crystallization peak becomes wider. It is suggested that the molecular chain of UHMWPE at higher cooling rate has poor mobility which is difficult to crystallize, resulting in a wider crystallization peak. At the same cooling rate, addition of modified filler increases the crystallization temperature of UHMWPE which indicates the presence of the heterogeneous nucleation of $\mathrm{PEW}-\mathrm{g}-\mathrm{CaCO}_{3}$. The higher crystallization enthalpy of UHMWPE is attributed to improved mobility of molecular chain of UHMWPE by oligomer-modified $\mathrm{CaCO}_{3}$.

In order to understand the effect of different modified$\mathrm{CaCO}_{3}$ on crystallization of UHMWPE, the non-isothermal crystallization behavior of UHMWPE composites filled by $\mathrm{CaCO}_{3}, \mathrm{AA}-\mathrm{CaCO}_{3}$ and $\mathrm{PEW}-\mathrm{g}-\mathrm{CaCO}_{3}$ are investigated by DSC. The plots of crystallization peak temperature and crystallization enthalpy versus cooling rate are shown in Fig. 3. It can be observed from Fig. 3 that the crystallization peak temperatures from high to low are $\mathrm{AA}-\mathrm{CaCO}_{3} /$
UHMWPE $>$ PEW-g-CaCO 3 /UHMWPE $\approx \mathrm{CaCO}_{3} / \mathrm{UHM}$ WPE $>$ UHMWPE at the same cooling rate. It is indicted that the heterogeneous nucleation of AA-CaCO 3 , PEW-g$\mathrm{CaCO}_{3}$ and $\mathrm{CaCO}_{3}$ can increase the crystallization peak temperature of UHMWPE and the heterogeneous nucleation of $\mathrm{AA}-\mathrm{CaCO}_{3}$ is higher than that of PEW-g-CaCO 3 and $\mathrm{CaCO}_{3}$. The crystallization enthalpy of UHMWPE composites is also higher than that of UHMWPE due to the heterogeneous nucleation of fillers. It can also be seen the crystallization enthalpy of PEW-g- $\mathrm{CaCO}_{3} / \mathrm{UHMWPE}$ is higher than that of $\mathrm{AA}-\mathrm{CaCO}_{3} / \mathrm{UHMWPE}, \mathrm{CaCO}_{3} /$ UHMWPE and UHMWPE at cooling rate of $5{ }^{\circ} \mathrm{C} \mathrm{min}^{-1}$. In our previous work [36], it is found that the oligomer-modified $\mathrm{CaCO}_{3}$ can improve the processability of UHMWPE. It is suggested that the presence of oligomer in the surface of PEW-g- $\mathrm{CaCO}_{3}$ is benefit to the mobility of molecular chain of UHMWPE to increase the degree of crystallization. However, the crystallization enthalpy of PEW-g-CaCO${ }_{3} /$ UHMWPE is lower than that of $\mathrm{AA}-\mathrm{CaCO}_{3} / \mathrm{UHMWPE}$ and $\mathrm{CaCO}_{3} / \mathrm{UHMWPE}$ at high cooling rate above $5{ }^{\circ} \mathrm{C} \mathrm{min}^{-1}$. It is considered that the mobility of molecular chain of UHMWPE is restricted in PEW-g- $\mathrm{CaCO}_{3} / \mathrm{UHMWPE}$ at 
Table 1 Kinetic parameters of UHMWPE and its composites from Jeziorny method

\begin{tabular}{|c|c|c|c|c|}
\hline Filler/wt $\%$ & $R /{ }^{\circ} \mathrm{C} \min ^{-1}$ & $t_{1 / 2} / \mathrm{min}$ & $n$ & $Z_{\mathrm{c}}$ \\
\hline \multirow[t]{5}{*}{0} & 5 & 0.92 & 4.7 & 1.10 \\
\hline & 10 & 0.56 & 5.3 & 1.37 \\
\hline & 15 & 0.40 & 4.8 & 1.36 \\
\hline & 20 & 0.33 & 5.3 & 1.35 \\
\hline & 25 & 0.29 & 5.4 & 1.32 \\
\hline \multirow[t]{5}{*}{5} & 5 & 0.89 & 4.9 & 1.16 \\
\hline & 10 & 0.53 & 4.9 & 1.37 \\
\hline & 15 & 0.37 & 5.2 & 1.37 \\
\hline & 20 & 0.32 & 5.0 & 1.32 \\
\hline & 25 & 0.29 & 4.7 & 1.27 \\
\hline \multirow[t]{5}{*}{10} & 5 & 0.83 & 5.4 & 1.28 \\
\hline & 10 & 0.47 & 4.9 & 1.47 \\
\hline & 15 & 0.39 & 5.6 & 1.45 \\
\hline & 20 & 0.31 & 5.2 & 1.37 \\
\hline & 25 & 0.28 & 5.2 & 1.32 \\
\hline \multirow[t]{5}{*}{15} & 5 & 0.8 & 5.2 & 1.28 \\
\hline & 10 & 0.48 & 4.8 & 1.46 \\
\hline & 15 & 0.37 & 5.4 & 1.44 \\
\hline & 20 & 0.30 & 4.9 & 1.36 \\
\hline & 25 & 0.26 & 5.0 & 1.32 \\
\hline \multirow[t]{5}{*}{20} & 5 & 0.80 & 5.0 & 1.26 \\
\hline & 10 & 0.48 & 5.0 & 1.45 \\
\hline & 15 & 0.37 & 5.3 & 1.41 \\
\hline & 20 & 0.30 & 4.7 & 1.33 \\
\hline & 25 & 0.26 & 5.0 & 1.31 \\
\hline \multirow[t]{5}{*}{25} & 5 & 0.91 & 4.6 & 1.11 \\
\hline & 10 & 0.50 & 4.1 & 1.33 \\
\hline & 15 & 0.39 & 4.5 & 1.32 \\
\hline & 20 & 0.33 & 4.6 & 1.29 \\
\hline & 25 & 0.29 & 4.8 & 1.27 \\
\hline
\end{tabular}

high cooling rate and the heterogeneous nucleation of PEW$\mathrm{g}-\mathrm{CaCO}_{3}$ is lower than that of $\mathrm{AA}-\mathrm{CaCO}_{3}$, resulting in the decrease in the crystallization enthalpy of PEW-g- $\mathrm{CaCO}_{3} /$ UHMWPE with an increase in cooling rate.

\section{Effect of modified- $\mathrm{CaCO}_{3}$ on non-isothermal crystallization kinetics of UHMWPE}

Some models were used to describe the non-isothermal crystallization kinetics of polymer and its blends and composites, including Ozawa, Jeziorny and Mo models, etc. In our work, effect of modified- $\mathrm{CaCO}_{3}$ on nonisothermal crystallization kinetics of UHMWPE was investigated by the Avrami theory modified by Jeziorny and Mo models.

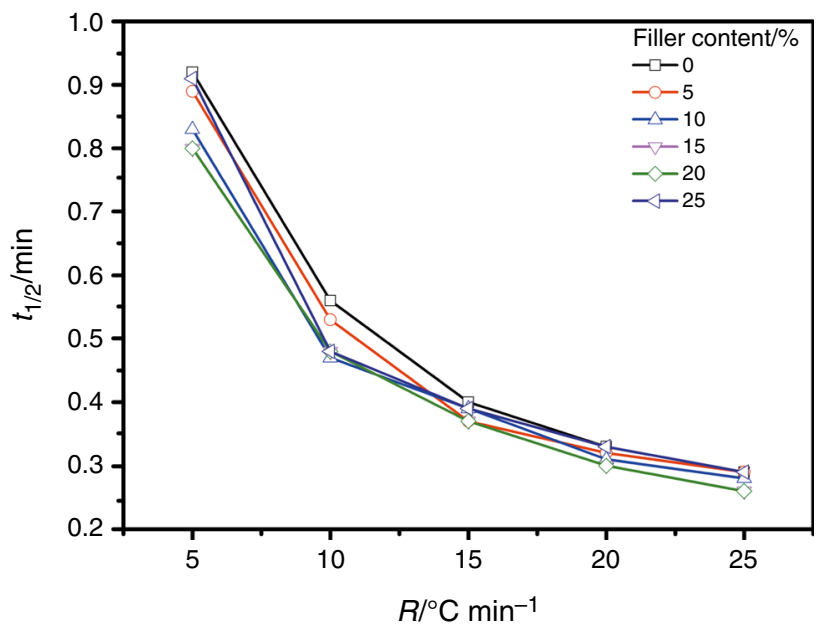

Fig. 6 Plots of half crystallization time versus cooling rate

Based on the Avrami theory modified by Jeziorny $[33,37,38]$, the non-isothermal crystallization kinetics can be described as follows:

$X_{\mathrm{t}}=1-\mathrm{e}^{-z_{\mathrm{t}} t^{n}}$

$\lg \left[-\ln \left(1-X_{\mathrm{t}}\right)\right]=n \lg t+\lg Z_{\mathrm{t}}$

$\lg Z_{\mathrm{c}}=\frac{\lg Z_{\mathrm{t}}}{R}$

where $n$ is the Avrami exponent, $Z_{\mathrm{t}}$ and $Z_{\mathrm{c}}$ are the Avrami and Jeziorny crystallization rate constants, respectively, $R$ is the cooling rate, the time-dependent relative crystallinity, $X_{\mathrm{t}}$, can be calculated by Eqs. 5 and 6 .

$X_{\mathrm{T}}=\frac{\int_{T_{0}}^{T} \frac{\mathrm{d} H}{\mathrm{~d} T} \mathrm{~d} T}{\int_{T_{0}}^{T_{\infty}} \frac{\mathrm{d} H}{\mathrm{~d} T} \mathrm{~d} T}$

$X_{\mathrm{t}}=\frac{\int_{t_{0}}^{t} \frac{\mathrm{d} H}{\mathrm{~d} t} \mathrm{~d} t}{\int_{t_{0}}^{t_{\infty}} \frac{\mathrm{d} H}{\mathrm{~d} t} \mathrm{~d} t}$

where $T_{0}$ and $t_{0}$ are the crystallization onset temperature and time, $T$ and $t$ are the arbitrary crystallization temperature and time, $T_{\propto}$ and $t_{\propto}$ are the ultimate crystallization temperature and time, respectively, $X_{\mathrm{T}}$ is the temperaturedependent relative crystallinity. If $\lg \left[\ln \left(1-X_{\mathrm{t}}\right)\right]$ is linear on $\lg t$, the Avrami exponent $n$ and the crystallization rate constant $Z_{\mathrm{t}}$ can be obtained by the slope and intercept. The crystallization rate constant $Z_{\mathrm{c}}$ can be calculated by Eq. (4).

Figures 4 and 5 are the representative curves of relative crystallinity of UHMWPE composites versus temperature or time, respectively. The plot of half crystallization time $\left(t_{1 / 2}\right)$ (Table 1) obtained from Fig. 5 versus cooling rate is shown in Fig. 6. It can be seen that the half crystallization time for all samples decreases with an increase in cooling rate, indicating that accelerating the cooling rate can increase the crystallization rate so that the crystallization 

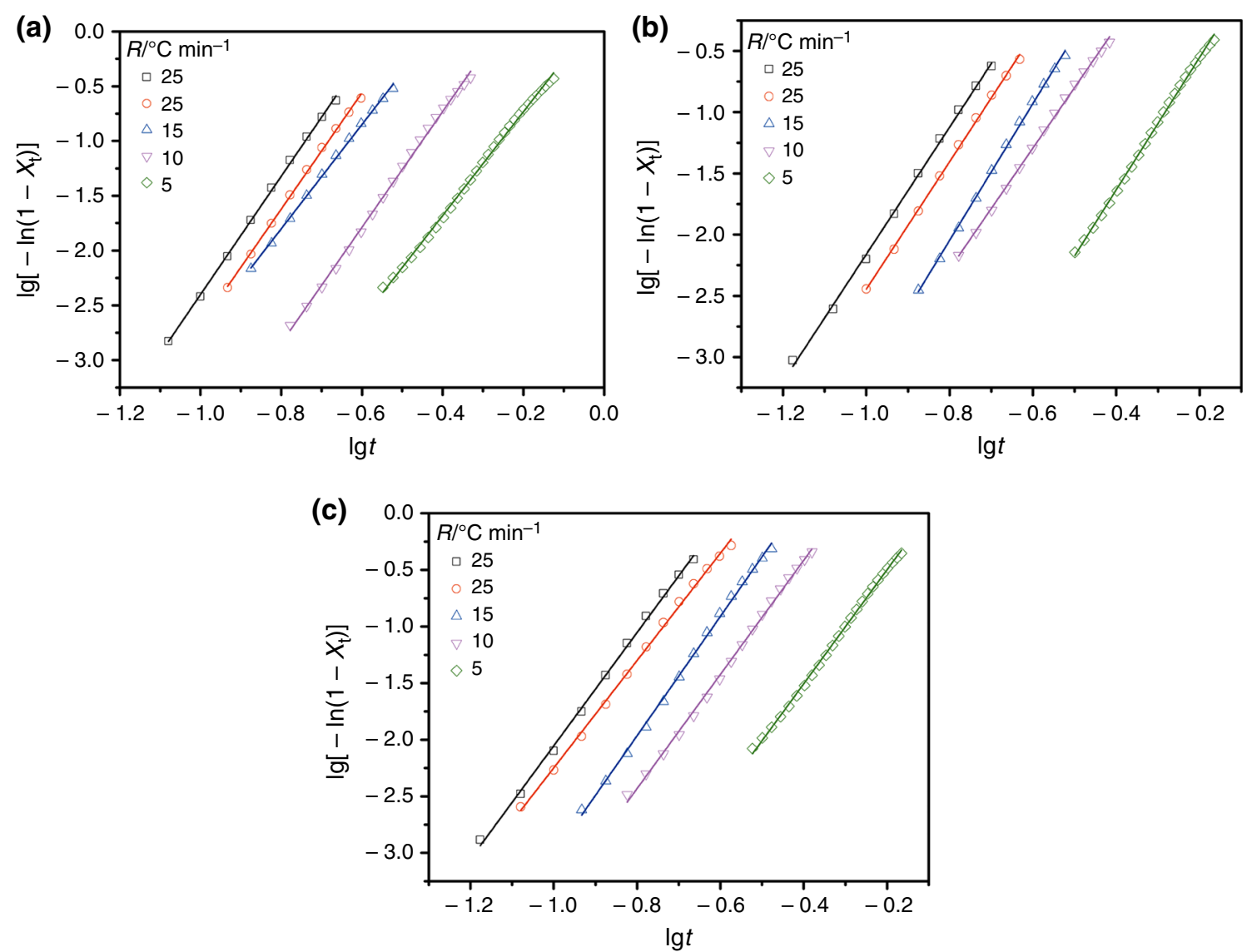

Fig. 7 Plots of $\lg \left[\ln \left(1-X_{\mathrm{t}}\right)\right]-\lg t$ for non-isothermal crystallization of PEW-g-CaCO $3 / \mathrm{UHMWPE}$ PEW-g-CaCO $3 / \mathrm{wt} \%$ : a 0 , b 10 and c 20

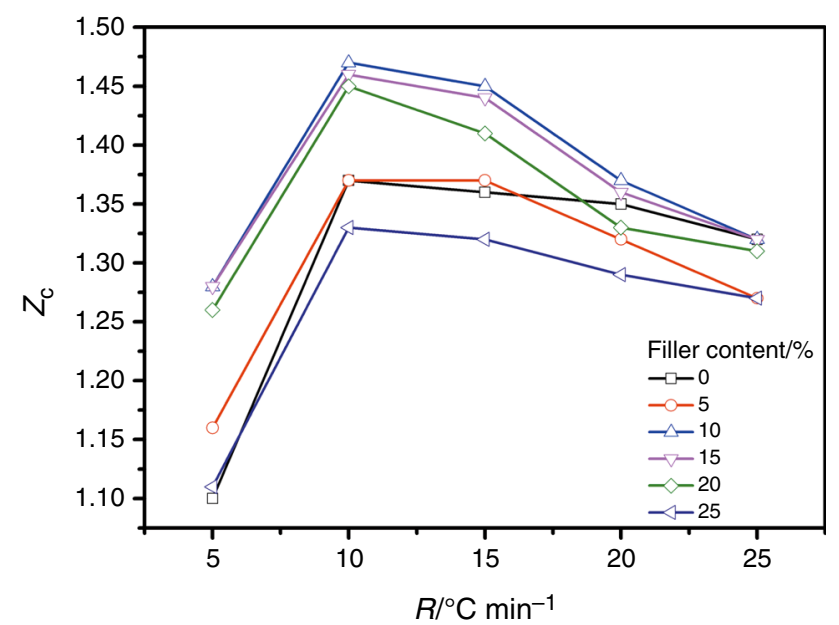

Fig. 8 Plots of crystallization rate constant versus cooling rate

time can be shortened. On the other hand, the half crystallization time of UHMWPE composites is lower than that of pure UHMWPE, indicating high crystallization rate in UHMWPE composites filled by PEW-g- $\mathrm{CaCO}_{3}$.

According to Eq. (3), the plots of $\lg \left[\ln \left(1-X_{\mathrm{t}}\right)\right]$ versus $\lg t$ are showed in Fig. 7. A good linear relation means that Jeziorny method is suitable to describe the non-isothermal crystallization kinetics of UHMWPE and its composites. The Avrami exponent $n$ and crystallization rate constant $Z_{\mathrm{t}}$ obtained by the slope and intercept are shown in Table 1. It can be observed from Table 1 that the crystallization rate constant of all samples increases with accelerating the cooling rate from 5 to $10{ }^{\circ} \mathrm{C} \mathrm{min}^{-1}$ and then decreases with an increase in the cooling rate. The Avrami exponent $n$ is about 5, which may be generated from their high viscosities, yielding a more complicated crystallization mechanism [32].

The relationship of crystallization rate constant of UHMWPE composites versus cooling rate is shown in Fig. 8. It can be seen that the crystallization rate constant of UHMWPE composites depends on the filler contents and cooling rate. At cooling rate of $10^{\circ} \mathrm{C} \mathrm{min}^{-1}$, UHMWPE and its composites exhibit maximum crystallization rate. At cooling rate above $10{ }^{\circ} \mathrm{C} \mathrm{min}{ }^{-1}$, the crystallization rate of UHMWPE decreases with an increase in cooling rate. At the filler content below $10 \mathrm{wt} \%$, the crystallization rate of UHMWPE composites increases with an increase in filler contents. At the filler content above $10 \mathrm{wt} \%$, the crystallization rate of UHMWPE composites decreases with an increase in filler contents. It is suggested that higher contents of filler and high cooling rate should hinder the 
(a)

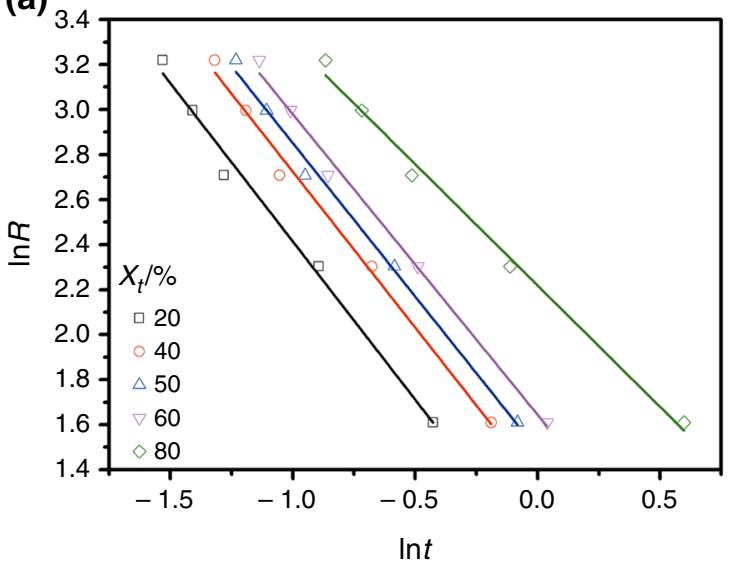

(b)

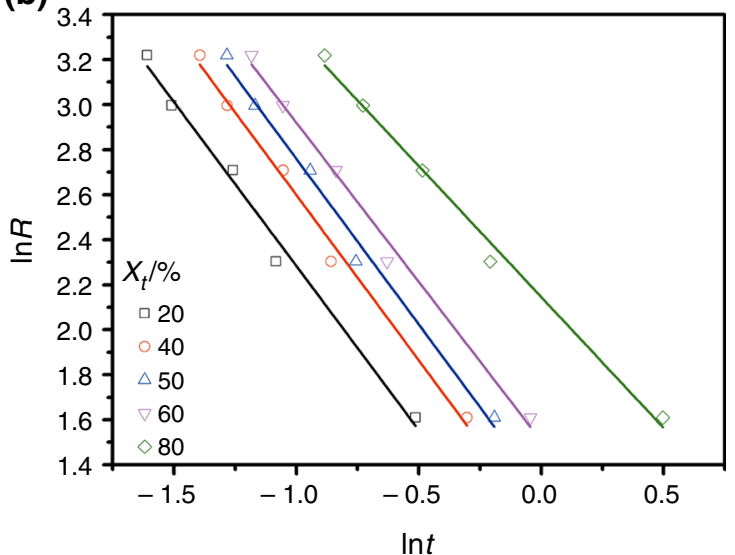

(c)

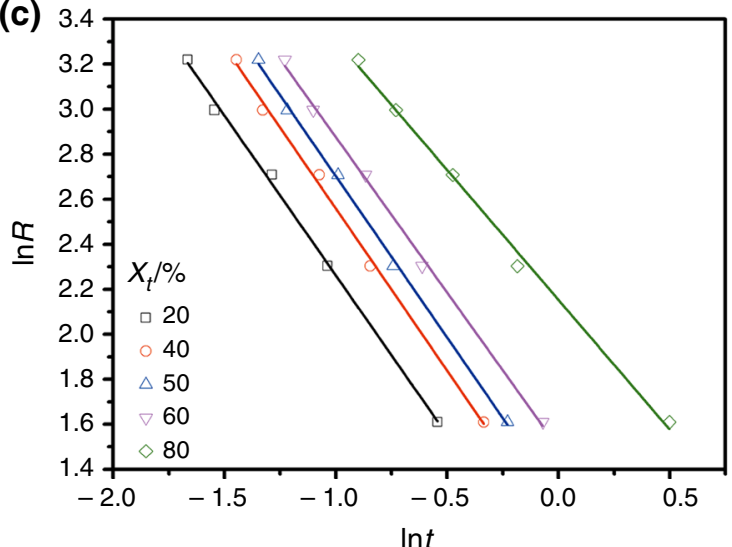

Fig. 9 Plots of $\lg R-\lg t$ for non-isothermal crystallization of PEW-g- $\mathrm{CaCO}_{3} / \mathrm{UHMWPE} \mathrm{PEW}-\mathrm{g}-\mathrm{CaCO}_{3} / \mathrm{wt} \%$ : a 0 , b 10 and $\mathbf{c} 20$

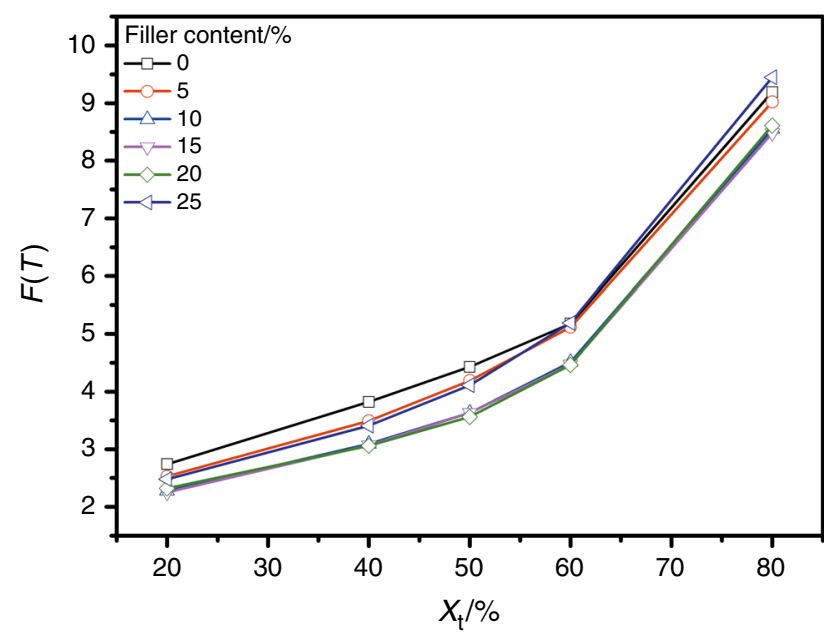

Fig. 10 Plots of $F(T)$ versus relative crystallinity

movement of molecular chain to decrease the crystallization rate of UHMWPE.

For the verification of the kinetic calculation results, we compare the experiment results with the calculation results by kinetic constants, shown in Fig. 5c. It can be found that the experiment results are agreed with the kinetic calculation results at relative crystallinity range of $0-50 \%$. Above $50 \%$ relative crystallinity, the experiment results deviated with the kinetic calculation results may be due to the effect of second crystallization.

Mo method is generally used to investigate the nonisothermal crystallization kinetics of polymer and its composites [33, 37, 38].

$\ln R=\ln F(T)-b \ln t$

where the $R$ is the cooling rate, $F(T)=\left[k / Z_{\mathrm{t}}\right]^{1 / m}$ can be used to characterize the crystallization rate. The value of $F(T)$ is bigger, the crystallization rate is slower. If $\lg R$ is linear on $\lg t$, the values of $F(T)$ can be calculated by the intercept.

Figure 9 is the plots of $\lg R$ versus $\lg t$ for UHMWPE and its composites. The plots of $\lg R$ have a good linearity with $\lg t$, which means that Mo method is suitable to describe the non-isothermal crystallization kinetics of UHMWPE and its composites. The plots of value of $F(T)$ calculated by the intercept versus relative crystallinity is shown in Fig. 10. The value of $F(T)$ increases with an increase in relative crystallinity, indicating that the crystallization rate becomes slower in high crystallinity. The $F(T)$ valve of 
pure UHMWPE is higher than those of all composites, also indicating that the $\mathrm{PEW}-\mathrm{g}-\mathrm{CaCO}_{3}$ can accelerate the crystallization of UHMWPE. Besides, the lower $F(T)$ of UHMWPE composites filled by $10-20 \%$ PEW-g-CaCO also indicated the higher crystallization rate, conforming to the conclusion obtained by Jeziorny method.

\section{Conclusions}

In order to improve the properties of UHMWPE composites filled by $\mathrm{CaCO}_{3}$, oligomer-modified $\mathrm{CaCO}_{3}$ was prepared and the effect of oligomer-modified $\mathrm{CaCO}_{3}$ on the nonisothermal crystallization behavior and crystallization kinetics of UHMWPE was investigated by differential scanning calorimetry. The results indicated that the addition of oligomer-modified $\mathrm{CaCO}_{3}$ increases the crystallization temperature and crystallization enthalpy of UHMWPE. It is attributed to the heterogeneous nucleation of oligomermodified $\mathrm{CaCO}_{3}$ and the improved mobility of molecular chain of UHMWPE by oligomer-modified $\mathrm{CaCO}_{3}$. Jeziorny and Mo methods can be used to describe the non-isothermal crystallization kinetics of UHMWPE and its composites. The crystallization rate of UHMWPE composites depends on the filler contents and cooling rate. UHMWPE and its composites exhibit maximum crystallization rate at cooling rate of $10{ }^{\circ} \mathrm{C} \mathrm{min}^{-1}$. The crystallization rate of UHMWPE decreases with an increase in cooling rate at cooling rate above $10{ }^{\circ} \mathrm{C} \min ^{-1}$. The crystallization rate of UHMWPE composites increases with an increase in filler contents at the filler content below $10 \mathrm{wt} \%$ and decreases with an increase in filler contents at the filler content above $10 \mathrm{wt} \%$. The higher contents of filler and high cooling rate should hinder the movement of molecular chain to decrease the crystallization rate of UHMWPE.

Acknowledgements We acknowledge the support of this work by the National Key Research and Development Program of China (Grant No. 2016YFB0302302), the Natural Science Foundations of China (51573213, 51303215) and the Pearl River Nova Program of Guangzhou (201610010163).

Open Access This article is distributed under the terms of the Creative Commons Attribution 4.0 International License (http://creative commons.org/licenses/by/4.0/), which permits unrestricted use, distribution, and reproduction in any medium, provided you give appropriate credit to the original author(s) and the source, provide a link to the Creative Commons license, and indicate if changes were made.

\section{References}

1. Khasraghi SS, Rezaei M. Preparation and characterization of UHMWPE/HDPE/MWCNT melt-blended nanocomposites. J Thermoplast Compos. 2015;28:305-26.
2. Visco A, Yousef S, Galtieri G, Nocita D, Pistone A, Njuguna J. Thermal, mechanical and rheological behaviors of nanocomposites based on UHMWPE/paraffin oil/carbon nanofiller obtained by using different dispersion techniques. JOM. 2016;68:1078-89.

3. Forster AL, Forster AM, Chin JW, Peng JS, Lin CC, Petit S, Kang KL, Paulter N, Riley MA, Rice KD, Al-Sheikhly M. Longterm stability of UHMWPE fibers. Polym Degrad Stab. 2015;114:45-51.

4. Chen L, Zheng K, Fang Q. Effect of strain rate on the dynamic tensile behaviour of UHMWPE fibre laminates. Polym Test. 2017;63:54-64.

5. Saikko V. Effect of contact area on the wear and friction of UHMWPE in circular translation pin-on-disk tests. J Tribol. 2017;139:061606.

6. Chu YY, Chen XG, Tian LP. Modifying friction between ultrahigh molecular weight polyethylene (UHMWPE) yarns with plasma enhanced chemical vapour deposition (PCVD). Appl Surf Sci. 2017;406:77-83.

7. Wang YZ, Yin ZW, Li HL, Gao GY, Zhang XL. Friction and wear characteristics of ultrahigh molecular weight polyethylene (UHMWPE) composites containing glass fibers and carbon fibers under dry and water-lubricated conditions. Wear. 2017;380-381:42-51.

8. Ruan FT, Bao LM. Mechanical enhancement of UHMWPE fibers by coating with carbon nanoparticles. Fiber Polym. 2014;15:723-8.

9. Tang G, Hu X, Tang TH, Claramunt C. Mechanical properties of surface treated UHMWPE fiber and $\mathrm{SiO}_{2}$ filled PMMA composites. Surf Interface Anal. 2017;49:898-903.

10. Kumar A, Bijwe J, Sharma S. Hard metal nitrides: role in enhancing the abrasive wear resistance of UHMWPE. Wear. 2017;378-379:35-42.

11. Sharma S, Bijwe JE, Panier S. Assessment of potential of nano and micro-sized boron carbide particles to enhance the abrasive wear resistance of UHMWPE. Compos B. 2016;99:312-20.

12. Sharma S, Bijwe J, Panier S, Sharma M. Abrasive wear performance of SiC-UHMWPE nano-composites-influence of amount and size. Wear. 2015;332-333:863-71.

13. He XL, Wang YH, Wang QT, Tang Y, Liu BP. Effects of addition of ultra-high molecular weight polyethylene on tiemolecule and crystallization behavior of unimodal PE-100 pipe materials. J Macromol Sci B. 2016;55:1007-21.

14. Pi L, Hu XY, Nie M, Wang Q. Role of ultrahigh molecular weight polyethylene during rotation extrusion of polyethylene pipe. Ind Eng Chem Res. 2014;53:13828-32.

15. Liu YM, Shi F, Bo L, Zhi W, Weng J, Qu SX. A novel alginateencapsulated system to study biological response to critical-sized wear particles of UHMWPE loaded with alendronate sodium. Mater Sci Eng C. 2017;79:679-86.

16. Riveiro A, Soto R, Del Val J, Comesana R, Boutinguiza M, Quintero F, Lusquinos F, Pou J. Laser surface modification of ultra-high-molecular-weight polyethylene (UHMWPE) for biomedical applications. Appl Surf Sci. 2014;302:236-42.

17. Souza VC, Oliveira JE, Lima SJG, Silva LB. Influence of vitamin $\mathrm{C}$ on morphological and thermal behaviour of biomedical UHMWPE. Macromol Symp. 2014;344:8-13.

18. Fang XD, Wyatt T, Hong YF, Yao DG. Gel spinning of UHMWPE fibers with polybutene as a new spin solvent. Polym Eng Sci. 2016;56:697-706.

19. Huang CY, Wu JY, Tsai CS, Hsieh KH, Yeh JT, Chen KN. Effects of argon plasma treatment on the adhesion property of ultra high molecular weight polyethylene (UHMWPE) textile. Surf Coat Technol. 2013;231:507-11.

20. Chukov DI, Stepashkin AA, Gorshenkov MV, Tcherdyntsev VV, Kaloshkin SD. Surface modification of carbon fibers and its effect 
on the fiber-matrix interaction of UHMWPE based composites. J Alloys Compd. 2014;586(SUPPL 1):S459-63.

21. Panin CV, Kornienko LA, Suan TN, Ivanova LR, Poltaranin MA. The effect of adding calcium stearate on wear-resistance of ultrahigh molecular weight polyethylene. Procedia Eng. 2015;113:490-8.

22. Puértolas JA, Kurtz SM. Evaluation of carbon nanotubes and graphene as reinforcements for UHMWPE-based composites in arthroplastic applications: a review. J Mech Behav Biomed Mater. 2014;39:129-45.

23. Yeh JT, Wang CK, Yu W, Huang KS. Ultradrawing and ultimate tensile properties of ultrahigh molecular weight polyethylene composite fibers filled with functionalized nanoalumina fillers. Polym Eng Sci. 2015;55:2205-14.

24. Dintcheva NT, Morici E, Arrigo R, Zerillo G, Marona V, Sansotera M, Magagnin L, Navarrini W. High performance composites containing perfluoropolyethers-functionalized carbonbased nanoparticles: rheological behavior and wettability. Compos B Eng. 2016;95:29-39.

25. Xu GY, Zhu QR. Studies on crystallization and melting behaviors of UHMWPE/MWNTs nanocomposites with reduced chain entanglements. Polym Polym Compos. 2017;25:495-506.

26. Doshi BN, Ghali B, Godleski-Beckos C, Lozynsky AJ, Oral E, Muratoglu OK. High pressure crystallization of vitamin e-containing radiation cross-linked UHMWPE. Macromol Mater Eng. 2015;300:458-65.

27. George A, Ngo HD, Bellare A. Influence of crystallization conditions on the tensile properties of radiation crosslinked, vitamin E stabilized UHMWPE. J Mech Behav Biomed Mater. 2014;40:406-12.

28. Shi XM, Bin YZ, Hou DS, Men YF, Matsuo M. Gelation/crystallization mechanisms of UHMWPE solutions and structures of ultradrawn gel films. Polym J. 2014;46:21-35.

29. Zuo JD, Liu SM, Zhao JQ. Cocrystallization behavior of HDPE/ UHMWPE blends prepared by two-step processing way. Polym Polym Compos. 2015;23:59-64.
30. Sattari M, Mirsalehi SA, Khavandi A, Alizadeh O, Naimi-Jamal MR. Non-isothermal melting and crystallization behavior of UHMWPE/SCF/nano-SiO ${ }_{2}$ hybrid composites. J Therm Anal Calorim. 2015;122:1319-30.

31. Liu C, Qiu HT, Liu CJ, Zhang J. Study on crystal process and isothermal crystallization kinetics of UHMWPE/CA-MMT composites. Polym Compos. 2012;33:1987-92.

32. Zhang CF, Zhu BK, Ji GL, Xu YY. Studies on nonisothermal crystallization of ultra-high molecular weight polyethylene in liquid paraffin. J Appl Polym Sci. 2006;99:2782-8.

33. Zhang CF, Bai YX, Gu J, Sun YP. Crystallization kinetics of ultra high-molecular weight polyethylene in liquid paraffin during solid-liquid thermally induced phase separation process. J Appl Polym Sci. 2011;122:2442-8.

34. Shen HL, Zhang N. Nonisothermal crystallization kinetics of HDPE/UHMWPE/n-HA composites. Adv Mater Res. 2011;194-196:2351-4.

35. Song SJ, Wu PY, Ye MX, Feng JC, Yang YL. Effect of small amount of ultra high molecular weight component on the crystallization behaviors of bimodal high density polyethylene. Polymer. 2008;49:2964-73.

36. Wu ZX, Zhang ZS, Mai K. Preparation and thermal property of ultrahigh molecular weight polyethylene composites filled by calcium carbonate modified with long chain. J Thermoplast Compos Mater. 2018. https://doi.org/10.1177/0892705718807955.

37. Jeziorny A. Parameters characterizing the kinetics of the nonisothermal crystallization of poly(ethylene terephthalate) determined by DSC. Polymer. 1978;19:1142-4.

38. Song J, Zhang H, Ren M, Chen Q, Sun X, Wang S, Zhang H, Mo Z. Crystal transition of nylon-12,12 under drawing and annealing. Macromol Rapid Commun. 2005;26:487-90.

Publisher's Note Springer Nature remains neutral with regard to jurisdictional claims in published maps and institutional affiliations. 